\title{
MODERNIZATION OF STRUCTURAL DESIGN OF OP-2000 SPRAYER USING APM WINMACHINE CAE SYSTEM
}

\author{
Alexey Slobodyuk, Sergey Strebkov, Andrey Bondarev \\ Belgorod State Agricultural University named after V. Gorin, Russia \\ asp122@yandex.ru, serwastr@gmail.com, av.bondarev@gmail.com
}

\begin{abstract}
The work is devoted to the modernization of the strain scheme of the sprayer OP-2000 frame preventing the destruction and residual deformation of the longerons using the CAE APM WinMachine system. The purpose of the research is to identify the causes and search for solutions to prevent identified failures. The problem is solved by constructing a finite element model of the structure and analyzing its stress-strain state using the Structure 3D CAE-system APM WinMachine calculation module and comparing the results with field sample activity. To determine the geometry of key structural elements, as well as adequate modeling of fastenings and proper load distribution, a 3D model of the sprayer frame has been built. For numerical experiments a complex plate-rod model has been developed, which allows accurately to reflect the geometry features of the structure and location of the supporting surfaces, the parameters of the partition grid were selected in such way to simulate adequately the loads. As a result of the calculations it was found that the cause of the frame longeron destruction is an insufficient margin of safety and stability under dynamic loading. The calculated parameters of the stress-strain state of the structure confirm the adequacy of the model. The areas with the maximum stress and strain values coincide with the real zones of destruction and residual deformations of the sprayer frame. To search for engineering solutions aimed at preventing identified failures, a series of numerical experiments was carried out in which the optimal configuration of the strain scheme was determined. During these calculations, decisions were made on the shape and location of the installation of additional structural elements that increase the strength, rigidity and stability of the frame. The trial testing of the sprayer, which has been repaired according to a modernized structural design in the field conditions 2018-2019, where we had found failures, did not reveal any new failures.
\end{abstract}

Keywords: destruction, residual deformations, operational failures, plate-rod model, structural strength.

\section{Introduction}

Modern crop cultivation technologies $[1 ; 2]$ contain the widespread use of plant nutrition with mineral fertilizers, as well as the use of chemical plant protection products. Reducing the soil cultivation cost leads to increase in the plant protection cost and under these conditions the reliable and trouble-free operation of boom sprayers of the OP-2000 type is one of the real ways to reduce the production costs.

The operating experience of this technique allows us to characterize it as reliable and lowmaintenance. However, during the operation of the OP-2000 in farms they faced with characteristic failures associated with the destruction and deformation of the sprayer frame (Figures 1-2). Failures are observed after transporting a fully refilled sprayer to the field along field roads.

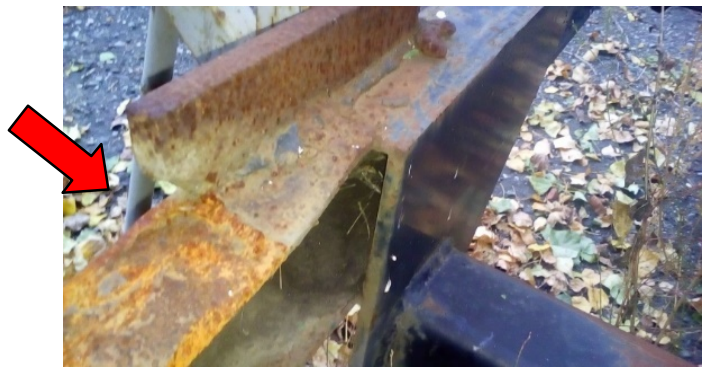

Fig. 1. Longerons destruction

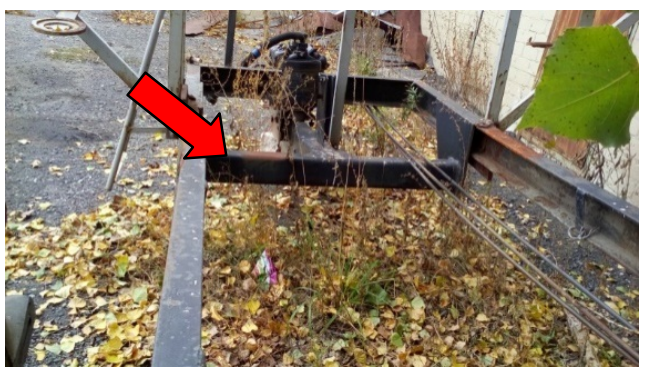

Fig. 2. Frame deformation

All detected defects are critical, i.e. they exclude the use of the machine for its intended purpose in accordance with the requirements of the operational documentation.

These failures are eliminated in the conditions of the household, but they require complete machine disassembly, which leads to prolonged downtime, agrotechnical terms violation and, therefore, to significant losses. 
Thus, the aim of this work is to determine the causes of the frame destruction and the development of an improved design, which will improve the reliability of the machine, reduce the cost of repairs and reduce losses from equipment downtime.

\section{Materials and methods}

The solution of the problem was carried out in the following order [3]:

- a finite element model of the working body rack was built and a number of numerical experiments were carried out to determine its stress-strain state under various loading conditions;

- on the basis of the research results and in comparison with the analysis data of field samples, the reason of structure destruction was found;

- a new series of calculations was carried out to search for a structural design that prevents failures in future.

\section{Building models of loading and fastening}

The frame structure consists of two longitudinal longerons and several cross-beams (also called "traverses" [4]), as well as fasteners and brackets for installing the tank, the boom system and aggregates. The structural elements are made of various types of profile iron and welded together.

The first step in the construction of design models is the determination of distinguished point of loading the structure and the supporting surfaces location. For this, it is necessary to build a 3D model, which will allow us to analyze the design, greatly simplify the creation of repair documentation and most importantly will allow us to build an adequate finite element model for analyzing the stress-strain state under various types of loading.

We built the model in the CAD system KOMPAS 3D. To do this, according to the results of measurements of the frame full-scale sample, the models of individual parts were built and then the resulting parts were combined into an assembly (Figure 3 ).

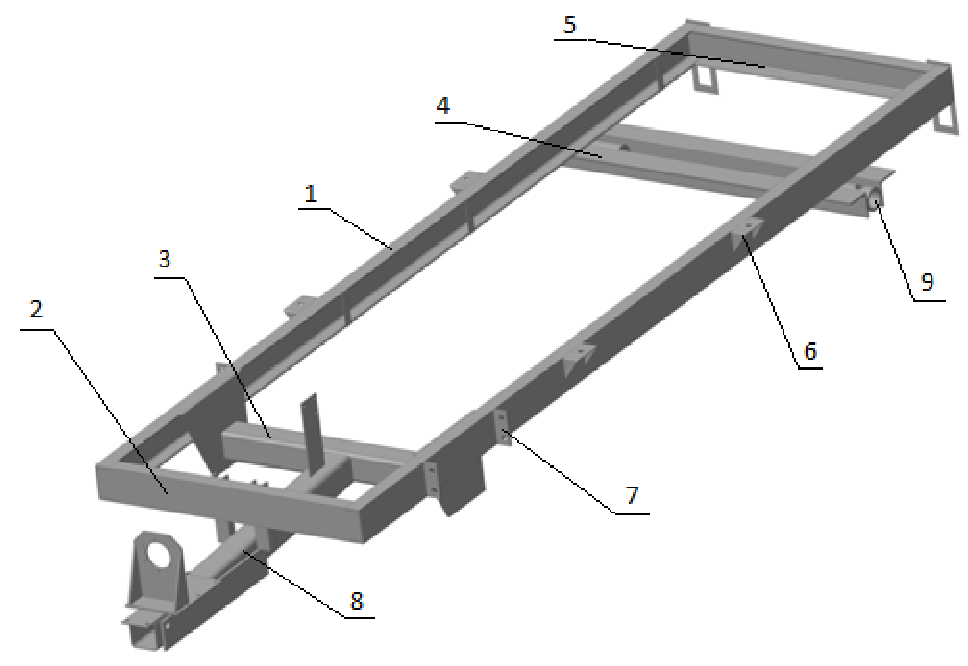

Fig. 3. 3D model of the sprayer frame: 1 - longeron; 2 - front traverse; 3 - middle traverse;

4 - traverse of carrier wheels; 5 - rear traverse; 6 - tank mounting bracket; 7 - service platform mounting brackets; 8 - drawbar; 9 - clip of fastening of a wheel semiaxis

As a result of the analysis of the real structure, as well as its 3D models, the points of application of loads to the frame, as well as their power, were established. The loads on the frame are composed of gravity from the tank with full refueling $(21840 \mathrm{~N})$, which is decomposed into four platforms along the upper shelf of the longeron channel section (pos. 1 Fig. 3). The bearing pads are located symmetrically at the middle traverse jaw (pos. 3, Fig. 3) in front and above the front corner of the rear traverse of the carrier wheels (pos. 4 Fig. 3). According to these sites, the force is distributed evenly - 
at $5460 \mathrm{~N}$ for each. The sites have a length of $300 \mathrm{~mm}$ along the channel shelf, which is established by the prints of the tank supports on the full-scale structure.

In addition, on the side surfaces of the longerons, we fixed the tank mounting brackets (pos. 6 Fig. 3 ) and service platform mounting brackets (pos. 7 Fig. 3), which also have to be under loading. The tank mounting brackets are affected by the tightening forces of the bolts of the clamps that surround the tank. These forces are directed upwards and amount to $1500 \mathrm{~N}$ for each bracket. The efforts are determined from the moment of tightening the nuts of the clamps given in the operational documentation [5].

The gravity force of the service platform affects on the brackets of the site vertically downward and $\mathrm{t}$ is $750 \mathrm{~N}$.

The rear traverse (pos. 5 Fig. 3) is loaded with the gravity of the frame of the hitching boom of the sprayer. This load falls in the middle of the rear beam and is $2700 \mathrm{~N}$.

As supports we take the front point of the drawbar beam (pos. 8 Fig. 3) of the sprayer frame and two clips of the wheel axle mounts (pos. 9 Fig. 3) on the rear traverse of the support wheels.

Thus, by analyzing the real structure, as well as its 3D model, we formed a loading diagram and a fixing scheme for the sprayer frame to calculate the stress-strain state.

\section{Analysis of the stress-strain state of the sprayer frame}

The construction of a model for calculating the stress-strain state by the finite element method [68] was carried out in the Structure 3D module of the CAE system APM WinMachine.

We have created a combined plate-rod finite element model that allows us to demonstrate accurately the design features and the application of loads to it (Figure 4).

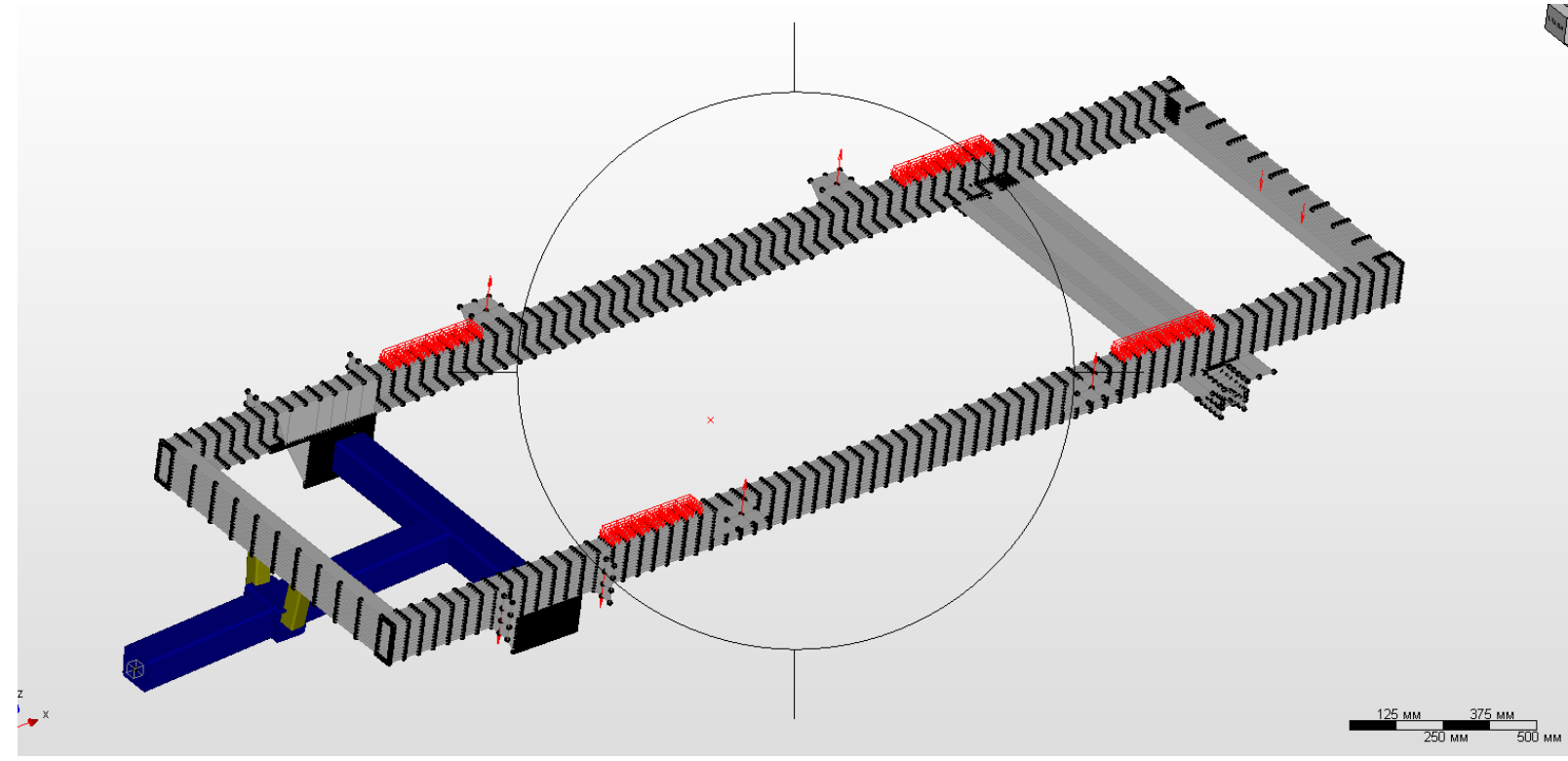

Fig. 4. Plate-rod finite element model

In this model longerons and traverses (except the front one) are modeled by plate elements of the corresponding thickness divided by a grid of nodes into separate components. The partition grid parameters were selected in such way as to subsequently more accurately simulate the application of loads.

The front traverse and drawbar beam were modeled with rods due to the features of loading and fastening of these elements.

Figure 4 also demonstrates the simulated side brackets and the loads to the structure in the form of separate forces to the nodes and forces distributed across the plates.

Fastenings in the form of articulated-fixed supports are installed at the end of the drawbar beam and at the ends of the traverse of the axle shafts of the wheels. 
Since it is known from the analysis of frame failures that they appear after transporting a fully equipped sprayer along field roads, the following points were included in the calculated load:

- external loads listed above;

- accounting of structure tare weight;

- additional load in the form of acceleration of the gravity force along the $\mathrm{z}$ axis (as a component of loading from inertia forces that arise when moving along irregularities).

\section{Results and discussion}

The calculation of the construction of the finite element model was carried out in the Structure 3D module of the APM WinMachine [9]. A static calculation, stability calculation and determination of the natural frequencies of the structure were done.

As a result of the linear static calculation of the structure, the stress-strain state of the structure is determined, the analysis of which allows us to conclude that the frame design does not provide a sufficient margin of safety under conditions of additional loading due to inertia forces.

Analysis of the obtained stress map (Figure 5) shows that the maximum level of stress occurs in the zone of attachment of the jaw of the middle beam, where the frame breaks down.

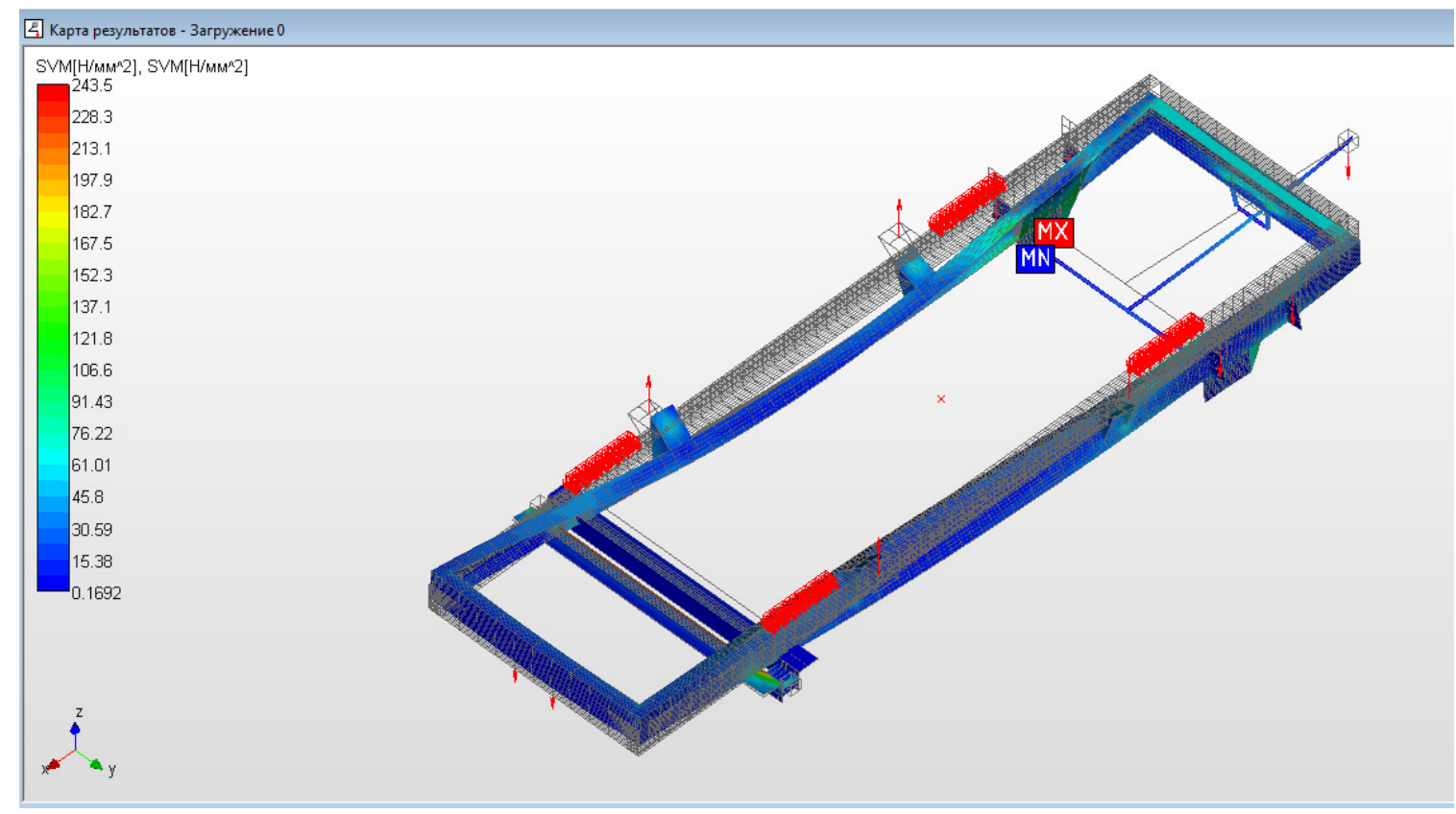

Fig. 5. Map of maximum principal stresses

The maximum value of the emerging principal strains of $240 \mathrm{MPa}$ exceeds the permissible value for steel 20, of which the frame is made.

The frame distinctive deformation is also noteworthy. The maximum displacement value (Figure 6 ) is $5 \mathrm{~mm}$. This displacement itself cannot be considered excessive for the given dimensions of the frame, so we can say that, if the strength was provided, then the rigidity would be sufficient.

Stability calculation was carried out under the static action of the load (without taking into account the inertia forces from the gravity force acceleration), when the strength is still provided, although with the minimum allowable safety factor (1.14). Moreover, the stability margin also has a very small value (1.08) and the form of stability loss corresponds to the strain pattern in Figure 5. Thus, the place of stability loss coincides with the actual place of residual deformations on the sprayer frame (Figure 2), which also confirms the reliability of the calculations.

Thus, the obtained results in comparison with the real fracture pattern demonstrate good convergence of the results, which confirms the adequacy of the constructed model. The analysis of the stress-strain state picture shows that the design does not provide enough margin of safety under conditions of additional loading by inertia forces under acceleration along the vertical axis. According to the calculation results, the observed residual deformations of the sprayer frame can be explained 
either by the loss of longeron stability, or by the construct falling into resonance [10] at a frequency of about $24 \mathrm{~Hz}$.

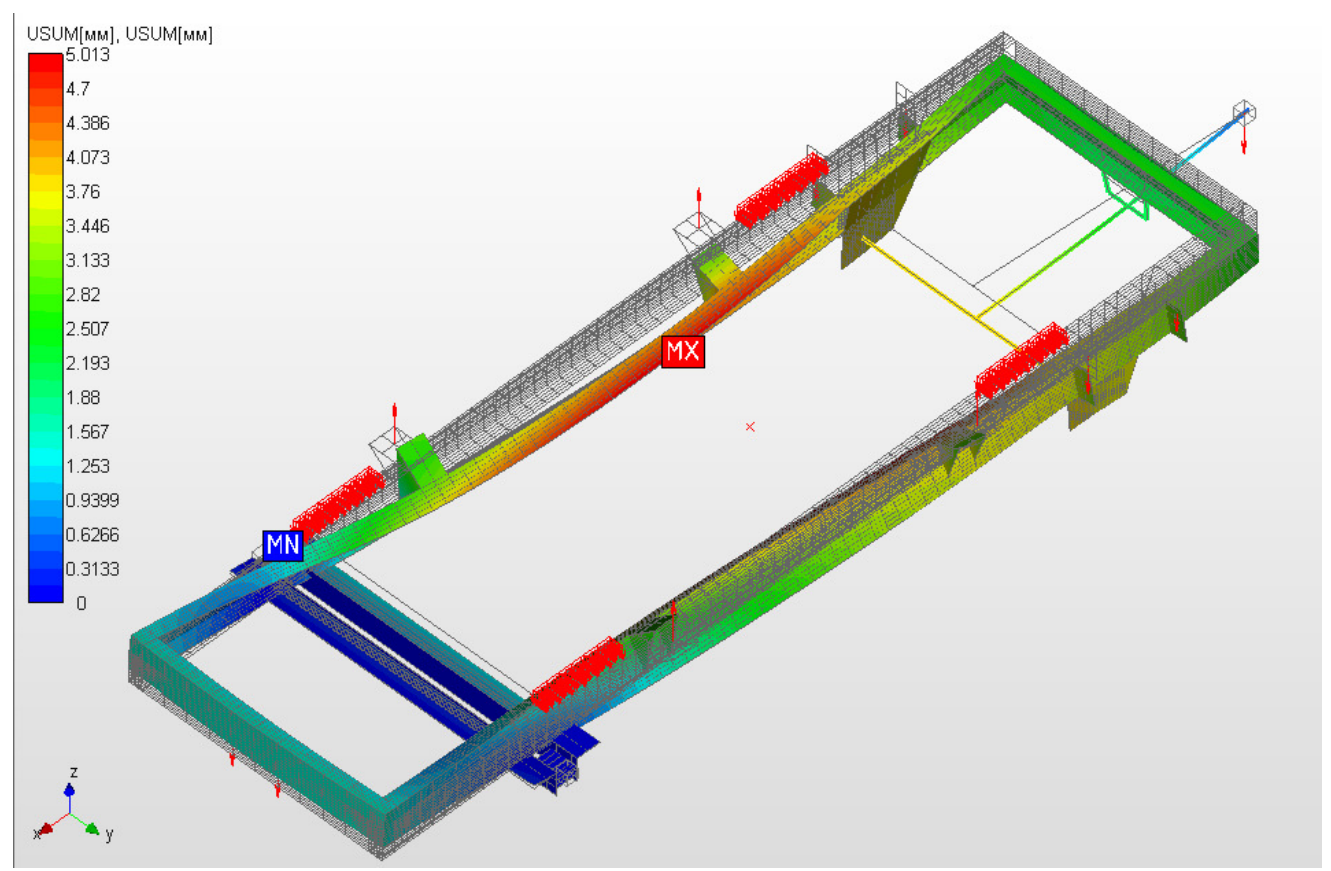

Fig. 6. Displacement map

\section{Justification for the parameters of the modernized construction}

Analysis of the stress map and the displacement map obtained during the calculation shows that the observed situation is due to the implemented loading scheme, namely, the applied load from the refilled tank over two sites on the upper shelf of the channel of each frame longeron. Not really high frame rigidity in the middle section without transverse elements (traverse) plays a significant role.

Therefore, we put forward a hypothesis suggesting that it is possible to reduce the maximum strain in the construction, if the load application scheme will be changed [11].

We proposed in the rear part of the frame to install additional platforms, which can redistribute part of the pressure from the tank. At the same time, in order to remove part of the load from the longerons and transfer it to the traverse of the wheel mounting, a stand was installed under the additional platform connecting the platform to the traverse (Figure 7).

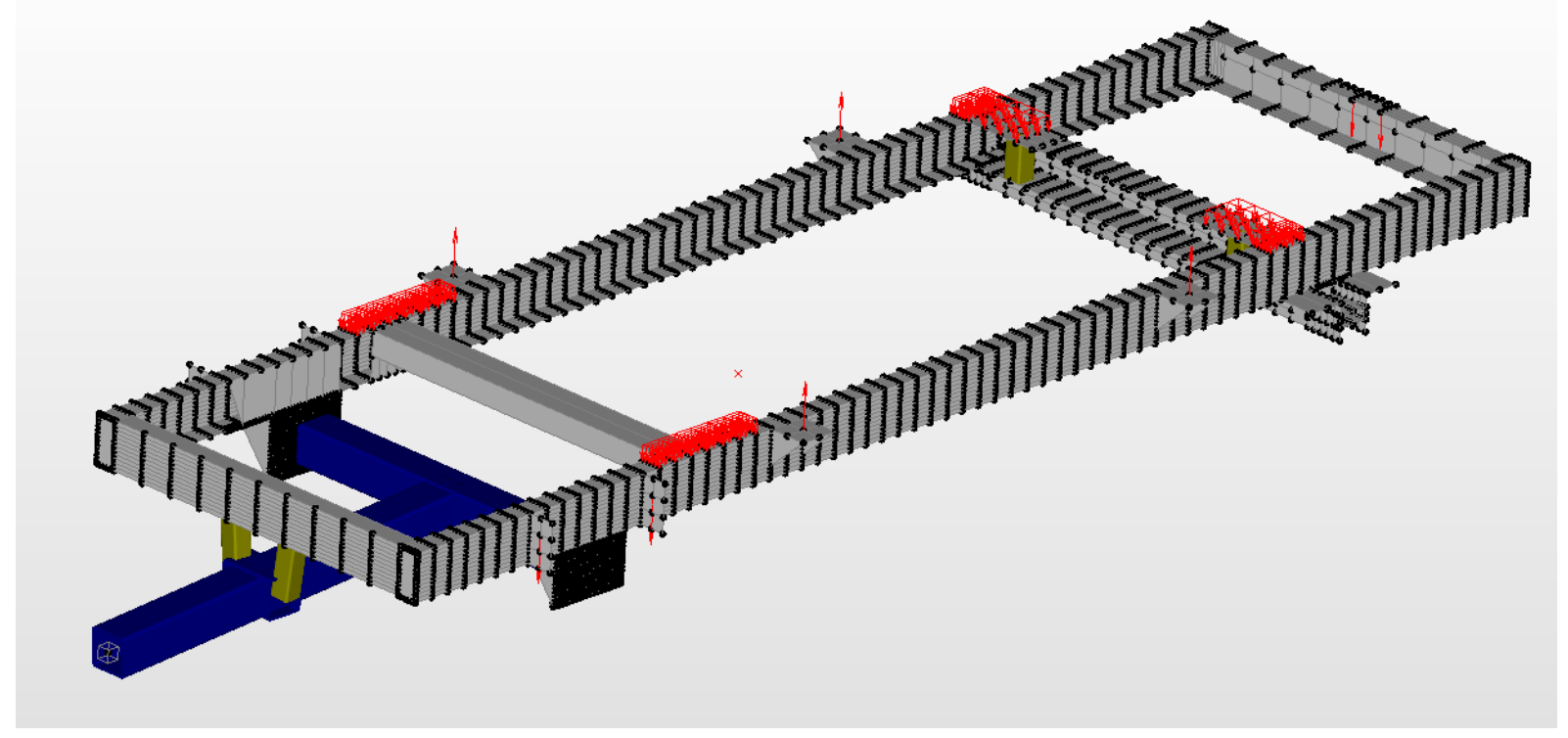

Fig. 7. Upgraded Frame Model 
To increase the frame rigidity in the middle section it is proposed to install an additional transversal element. Structurally an additional traverse can be installed on the longeron side with 350 $\mathrm{mm}$ long from the attachment point of the drawbar jaw. This length of the section is due to the fact that at a distance more than $350 \mathrm{~mm}$ from the attachment place of the jaw between the frame longerons there are structural elements of the tank.

To determine the optimal parameters of the new design we carried out a series of calculations in which the additional traverse was successively moved from the attachment point of the intermediate traverse jaw with a step of $50 \mathrm{~mm}$.

During the calculations the maximum point of the main strains in the frame design and the maximum value of the displacements of the frame elements depending on the installation distance of the additional traverse from the mounting point of the jaw were fixed.

The obtained dependences are presented in Figure 8 and Figure 9.

As it can be seen from the figures, the installation of additional elements on the frame itself significantly reduces the maximum level of acting strains. In this case, the removal of the additional traverse from the attachment point of the jaw leads first to a certain increase in the level of the maximum primary stress and then to its decreasing to the level of 103-105 MPa. The maximum deformation of the structure is monotonously reduced.

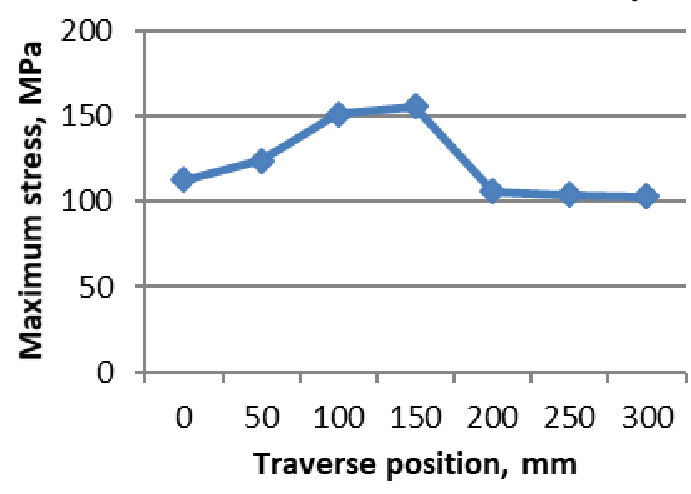

Fig. 8. Maximum primary stress change

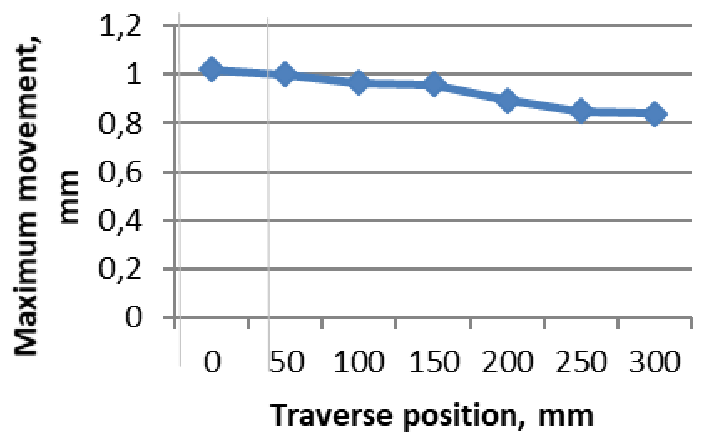

Fig. 9. Maximum displacement change

Thus, the calculations have shown that the optimal installation location of the additional traverse is a distance of $200 \mathrm{~mm}$ from the jaw attachment point of the intermediate traverse of the sprayer frame.

\section{Practical implementation of the proposed activities}

In accordance with the measures to modernize the design of the OP-2000 sprayer frame in the conditions of Maznev farm one unit of the specified equipment was repaired. After field work the sprayer was disassembled. The frame defect identification revealed a failure in the form of permanent deformation of the right longeron. After frame reconstruction between longerons in the determined place an additional intermediate traverse (Figure 10) was welded from a bent channel 140x80 and base plates were welded on it.

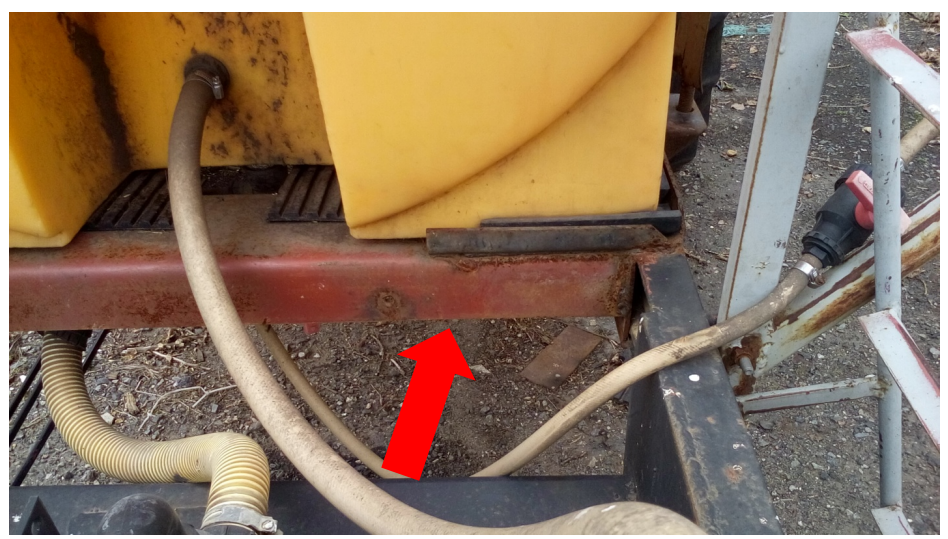

Fig. 10. Installed additional traverse 
Further support platforms were welded to the right and left longerons and racks were welded between them and the wheel traverse (Figure 11).



Fig. 11. Installed left mounting pad with support

In operation of the modernized sprayer during the field season of 2018 in the same modes as before the reinforcement of the structure, no failure of the frame was recorded due to previously observed defects.

\section{Conclusions}

1. The calculations performed on the constructed models showed that structural failures occur as a result of insufficient strength and loss of stability under dynamic loading under operating conditions.

2. Analysis of the obtained stress-strain state of the frame and computational experiments made it possible to propose constructive measures to ensure the operability of the structure.

3. Field inspection of the modernized design in the field confirmed the correctness of the measures taken to ensure the failure-free operation of the sprayer frame.

\section{References}

[1] Коледа, К.В. Современные технологии возделывания сельскохозяйственных культур: рекомендации (Modern technologies of crop cultivation: recommendations )/ K.V. Coleda and others; under the ed. K.V. Coleda, A.A. Duduk. Grodno. SSAU Publ., 2010. 340 p. ISBN 978985-6784-71-5 (In Russian).

[2] Wildflush I. R. et.al. Современные технологии возделывания сельскохозяйственных культур: учебно-методическое пособие (Modern technologies of crop cultivation: teaching aid), under the editorship of I.R. Wildflush, P. A. Saskevich. Gorky. BSAA Publ., 2016. 383 p. ISBN 978-985-467-610-4. (In Russian).

[3] Slobodyuk A., Strebkov S., Bondarev A. Failure examination of disc header workpoints using CAE-system APM WINMACHINE, Engineering for Rural Development./ Proceedings, Vol/ 17, : Изд-во /Latvia University of Life Sciences and Technologies, Jelgava, 2018, pp. 837-843. DOI: 10.22616/ERDev2018.17.N135.

[4] Гришкевич, А. И. Автомобили: Конструкция, конструирование и расчёт. Системы управления и ходовая часть (Cars: design, construction and calculation. Control systems and chassis ) / A. I. Grishkevich. Minsk. "Highest School" Publ., 1987. 200 p. (In Russian).

[5] Опрыскиватель ОП-18-2000. Техническое описание и инструкция по эксплуатации (Sprayer OP-18-2000. Technical description and user manual) // ROSAGROMIR.RU: official website of the company, 2016. [online][11.02.2020] Available at:

http://www.rosagromir.ru/catalog/mashiny-dlya-vneseniya-udobreniy-i-zashchity- rasteniy (In Russian).

[6] Сегерлинд, Л. Применение метода конечных элементов: пер. с англ. (Application of the finite element method: trans. from English )/ ed. B. E. Pobedry. Moscow. Mir Publ. 1979. 392 p.

[7] Bhavikatti S.S. Finite Element Analysis. New Delhi: New Age International, 2005, 347 p. 
[8] Baker A.J. Finite Elements: Computational Engineering Sciences. Chichester: John Wiley \& Sons, 2012, 288 p.

[9] Замрий, А. А. Проектирование и расчет методом конечных элементов в среде АРМ Structure3D (Design and calculation by the finite element method in the environment APM Structure3D)/ A.A. Zamrii. Moscow. APM Publ., 2010. 376 p. (In Russian).

[10] Lees A.W. Vibration Problems in Machines: Diagnosis and Resolution. New York: CRC Press, Taylor \& Francis Group, 2016, XVI, 321 p.

[11]Мазнев А.Ф. Анализ причин отказов рамы опрыскивателя ОП-2000 (Analysis of failure causes of the sprayer frame OP-2000)/ A.F. Maznev, A.P. Slobodyuk // Abstracts report. Int. Stud. scientific conf. Feb 7-8 2017 Belgorod State Agricultural University. T.2. Mayskiy, 2017. p. 41 (In Russian). 